\title{
DETERMINATION OF THE BIOMASS PRODUCTION AND CARBON SEQUESTRATION CAPACITY OF WET - ZONE FORESTS IN SRI LANKA
}

by

Wahala Mudiyanselage Palitha Sampath Bandara Wahala

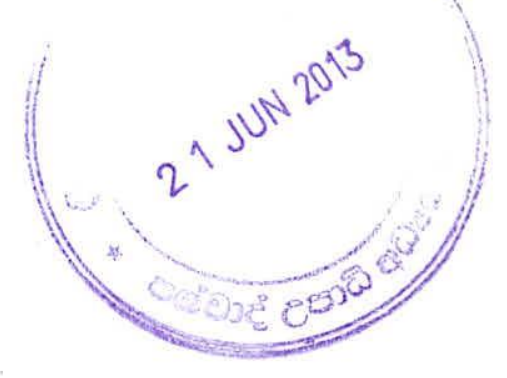

Thesis submitted to the University of Sri Jayewardenepura for the award of the Degree of Doctor of Philosophy in forestry on $10^{\text {th }}$ May 2013. 


\section{DECLARATION}

"The work described in this thesis was carried out by me under the supervision of Prof. Hemanthi Ranasinghe and Prof. H. S. Amarasekera (interim supervisor) of the Department of Forestry and Environmental Science at the University of Sri Jayewardenepura, Nugegoda, Sri Lanka and a report on this has not been submitted in whole or in part to any university or any other institution for another degree or diploma"

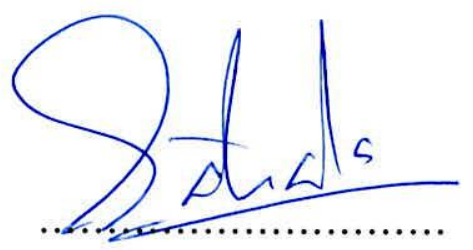

W M P S B Wahala

$10^{\text {th }}$ May 2013 


\section{SUPERVISORS'NOTE}

"We certify that the above statement made by the candidate is true and that this thesis is suitable for submission to the University for the purpose of the evaluation."

Supervisor:

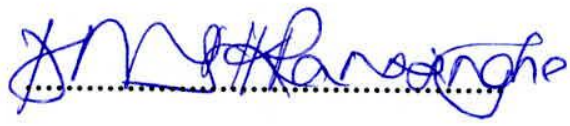

Prof. D.M.S.H.K. Ranasinghe

Department of Forestry and

Environmental Science

University of Sri Jayewardenepura

Date: $19 / 06 / 20 / 3$
Interim Supervisor:

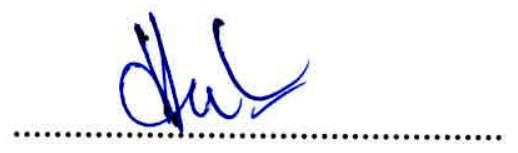

Prof. H. S. Amarasekera

Department of Forestry and

Environmental Science

University of Sri Jayewardenepura

Date: $\quad 19106 / 2013$ 


\section{ACKNOWLEDGEMENTS}

This work would not be possible without the help and support of many individuals, many of whom I may forget to mention and I apologize if that occurs.

First, I would like to express my deepest gratitude and I am greatly honored to Prof. Hemanthi Ranasinghe, Professor of Forestry and Environmental Science of the Department of Forestry and Environmental Sciences, University of Sri Jayewardenepura, for being my internal supervisor and suggesting me this research topic that has national global importance. Without her suggestions, help and guidance my approach on this study would not be successful. She has been a great inspiration not only for this study but also for my entire academic career.

I wish to extent my gratitude to Prof. W.A.J.M. De Costa, Professor of Crop Science of the Faculty of Agriculture, University of Peradeniya, for providing me the expertise guidance and information, Hemispherical photography camera setup and the HemiView 2.1 Canopy Analysis computer software for this study, and specially for the facilitating me to carry out seedling level photosynthesis estimation at crop physiology lab of the agriculture faculty of University of Peradeniya.

I wish to express my heartiest gratitude to Prof. Hiran S Amarasekera, Professor of Department of Forestry and Environmental Sciences, University of Sri Jayewardenepura 
for being the internal supervisor during Prof Hemanthi's Sabbatical leave period in year 2011. More than a supervisor, you were a spirit for me in many mile stones in my life.

I would like to extend my sincere thanks to Mr. I. D. Wijesinghe, Mr. Suresh Weththasinghe and Mr. Suranjan who are the technical officers in the department for their cooperation in providing me with the field equipments and to the rest of the staff of the Department of Forestry and Environmental Science, University of Sri Jayewardenepura. Also I wish to thank Mr. Gemunu, Mrs. Janakie, Mr. Aththanayake and other technical staff at the Faculty of Agriculture, University of Peradeniya for the support given me specially during the measurement of photosynthetic parameters of seedlings with LICOR 6400 portable photosynthesis measurement system.

I wish to give my special thank to Mr. Dharshana, and Dr. Thilantha Dammalage of the Faculty of Geomatics of Sabaragamuwa University of Sri Lanka, for their technical guidance during the development of vegetation indices using MODIS data with ENVI and ArcGIS computer softwares.

I am appreciative to those who have provided financial support for this work. This project was initially funded by the NSF grant no RG/2003/FR/01.

I am also grateful to the Forest Department of Sri Lanka and the Department of Wildlife Conservation of Sri Lanka for providing me the permission to carry out my field work at Forest Reserves and National parks. 
I must thank to the Department of Meteorology, Sri Lanka for providing me the necessary data for the calculation which direct my study for the success.

I specially would like to thank Mr. Nilantha Vishwanath who gave me the finest support by giving me his own vehicle for the field work and all the supports gave me at the field.

I am grateful to pen these few words to thank Mr. Chithrasekera at Kanneliya and the forest officers at the field station and Wimale at Sinharaja who was the caretaker at Sinharaja field station during my work period at Sinharaja. Thank you for giving me accompanies and genuine and kind helps in many ways when I was at field alone. I would like to extend my sincere thanks to Prof. Swarna Piyasiri, the Dean, Faculty of Graduate Studies, Prof. Sadun Senerath, Chairperson, Board of Life Science for the assistance gave throughout the study period. I would also like to thank Mr. Risvi, and Ms. Sachintha at Faculty of Graduate faculty, University of Si Jayewardenepura for their friendly and keen administrative support done for me in various ways.

Last but not least, I would like to thank my mother and beloved family members, for their love and moral support rendered during the whole period.

Finally I am surprised and pleased to have an unseen spiritual support had with me all the time like the shadow of mine to overcome the various obstacles came out the way. 


\section{CONTENTS}

$\begin{array}{ll}\text { DECLARATION } & \text { ii }\end{array}$

SUPERVISORS'NOTE

ACKNOWLEDGEMENTS

CONTENTS $\quad$ v

LIST OF TABLES Xiv

LIST OF FIGURES $\quad$ xvi

DEDICATION $\quad$ j $\quad$ xxv

$\begin{array}{ll}\text { ABSTRACT } & \text { xxvi }\end{array}$

CHAPTER ONE : INTRODUCTION

$\begin{array}{ll}1.1 & \text { Carbon sequestration }\end{array}$

$\begin{array}{lll}1.2 & \text { Forests as a carbon sink } & 4\end{array}$

1.3 Natural forests in Sri Lanka 5

$\begin{array}{lll}1.4 & \text { Objective of the study } & 7\end{array}$

$\begin{array}{lll}\text { 1.4.1 Specific objectives } & 7\end{array}$ 
2.1 Global warming and climate change

2.2 The Consequences of climate change and climate variability

$\begin{array}{lll}2.3 & \text { Kyoto Protocol } & 13\end{array}$

2.3.1 Clean Development Mechanism and current situation in Sri Lanka 14

2.3.2 REDD and REDD ${ }^{+}$

2.4 Global carbon cycle

$\begin{array}{lll}2.5 & \text { Carbon sequestration } & 18\end{array}$

2.5.1 Terrestrial ecosystems as a carbon sink 19

2.5.2 Forests as a carbon sink - Global estimates 22

2.5.3 Carbon sink in natural forests in global scale 23

2.5.4 Carbon sink in forest plantations in global scale 29

2.5.5 Forests as a carbon sink - Estimates in Sri Lanka 30

2.6 Net Ecosystem Exchange 34

$\begin{array}{lll}2.6 .1 & \text { Ecosystem respiration } & 35\end{array}$

$\begin{array}{lll}2.6 .2 & \text { Soil respiration } & 36\end{array}$

2.6.3 Methods to estimate net ecosystem $\mathrm{CO}_{2}$ exchange 36

2.7 Net Primary Production and Gross Primary Production 38

2.8 Photosynthesis - The primary process of biomass production 46

$\begin{array}{lll}2.8 .1 & \text { Plant respiration } & 47\end{array}$ 
2.8.3 Photosynthetic properties of tropical forest trees

2.8.4 Photosynthetic light response curve

2.8.4.1 Rectangular Hyperbola

2.8.4.2 Non-rectangular Hyperbola

2.8.4.3 Asymptotic exponential curve

2.8.5 Estimation of canopy photosynthesis

2.9 Radiation Use Efficiency (RUE)

2.9.1 Canopy photosynthetic radiation use efficiency

2.9.2 Methods of determining the canopy RUE

2.9.3 Big leaf model

2.9.4 Two leaf model

2.10 Forest canopy structure and characteristics

2.10.1 Leaf Area Index

2.11 Forest canopy light environment

2.11.1 Gap fraction

2.11.2 Canopy radiation interception

2.13.1 PRI and RUE estimation

2.13.2 Normalized Different Vegetation Index 
2.14 Tropical forest resource - Global situation

3.1 Site description

3.1.1 Sinharaja Forest Reserve

3.1.1.2 Topography

3.1.1.3 Geology and soil

3.1.1.5 Forest condition and main vegetation types in Sinharaja

3.1.2 Kanneliya Forest Reserve

3.1.2.1 Extent and Location

3.1.2.2 Topography

3.1.2.3 Geology and soil

3.1.2.4 Climate

3.1.2.5 Forest condition 
$\begin{array}{lll}\text { 3.1.3.3 Climate } & 96\end{array}$

3.1.3.4 Forest condition and main vegetation types in Knuckles forest 96

3.1.4 Peak Wilderness Sanctuary 98

3.1.4.1 Extent and Location 98

$\begin{array}{ll}\text { 3.1.4.2 Topography } & 100\end{array}$

$\begin{array}{lll}\text { 3.1.4.3 Geology and soil } & 100\end{array}$

$\begin{array}{lll}\text { 3.1.4.4 Climate } & 100\end{array}$

$\begin{array}{ll}\text { 3.1.4.5 Forest condition } & 101\end{array}$

$\begin{array}{ll}\text { 3.1.5 Horton Plains National Park } & 104\end{array}$

3.1.5.1 Extent and Location 104

$\begin{array}{lll}\text { 3.1.5.2 Topography } & 104\end{array}$

$\begin{array}{lll}\text { 3.1.5.3 Geology and soil } & 105\end{array}$

$\begin{array}{lll}\text { 3.1.5.4 Climate } & 105\end{array}$

$\begin{array}{lll}\text { 3.1.5.5 Forest condition } & 105\end{array}$

$\begin{array}{ll}3.2 & \text { Rationale and principle of the study } \\ \end{array}$

$\begin{array}{ll}\text { 3.2.1 Physiology of biomass production } & 110\end{array}$

$\begin{array}{ll}\text { 3.2.2 Radiation interception by forest canopy }\left(R_{I}\right) & 111\end{array}$

$\begin{array}{lll}\text { 3.2.3 PhRUE of forest canopies } & 112\end{array}$

3.3 Measurement of intercepted radiation using hemispherical photography 112

3.3.1 Equipments and software for the acquisition and analysis of hemiphotos 113

$\begin{array}{ll}\text { 3.3.1.1 Spesifications of equipments } & 113\end{array}$

3.3.1.2 Hemi View 2.1canopy analysis software 114

$\begin{array}{lll}\text { 3.3.2 Sampling design for hemispherical photography } & 115\end{array}$ 
3.3.4.1 Pre preparation of images

3.3.4.2 Align images

3.3.4.5 Solar model

\subsubsection{Calculation settings}

3.3.5 Calculating results

3.4 Determination of RUE values for forest canopies

3.4.1 Photosynthesis measurements of seedlings

3.4.2 Determination of canopy level PhRUE

3.5.1 Acquisition and processing of MODIS reflectance data to develop PRI 128

3.5.2 Deriving relationship between PRI and PhRUE

3.6 Development of vegetation indices

3.6.1 Normalize d Difference Vegetation Index

3.6.2 Enhanced Vegetation Index

3.7 Estimation of biomass production rates from intercepted PAR and PhRUE 130

3.8 Estimation of carbon sequestration rates 
3.9.1 Analysis of variance of canopy characteristics and light environment 131

$\begin{array}{lll}3.9 .2 & \text { Regression analysis } & 131\end{array}$

3.9.3 Development and analysis of VI's 132

4.1.1 Variation of canopy PAR interception between different vegetation types

4.1.2 Variation of forest canopy PAR interception between study sites

4.1.3 Within site variation of canopy PAR interception

4.2 Leaf Area Index (LAI)

4.2.1 LAI variation between different vegetation types

4.2.2 Variation of LAI between study sites

4.2.3 Within site variation of LAI

4.2.4 LAI variation with elevational gradient

4.2.5 Relationship between LAI and fractional radiation interception by forest canopies

4.3.2.1 Variation of PRI between different vegetation types 
4.4 Net Primary Productivity (NPP) of forest canopies

4.4.1 Variation of NPP between different vegetation types

4.4.2 Variation of NPP of between study sites

4.4.3 Within Site variation of canopy level NPP

4.5 Net biomass production rates

4.5.1 Net biomass production rates of different vegetation types

4.5.2 Net biomass production rates in different study sites

4.6 $\quad \mathrm{CO}_{2}$ Sequestration rate

4.6.1 $\mathrm{CO}_{2}$ Sequestration rate of different vegetation types

4.6.2 $\mathrm{CO}_{2}$ Sequestration rates in study sites

4.8.1 Relationship between $\mathrm{CO}_{2}$ sequestration and NDVI

4.8.2 Relationship between $\mathrm{CO}_{2}$ sequestration and EVI

4.9 Total $\mathrm{CO}_{2}$ sequestration capacity in wet zone forests 
5.3 Forest canopy characteristics and solar radiation interception

5.3.1 Variation of LAI

5.3.2 Total solar radiation interception by forest canopy

5.4 Photosynthetic Radiation Use Efficiency of natural forests

5.5 Relationship between PRI and PhRUE

5.6 NPP, net biomass production and carbon sequestration

5.7 Relationship between $\mathrm{CO}_{2}$ sequestration rate and VI's

6.1 Conclusions

6.2 Recommendations 


\section{LIST OF TABLES}

Table 2.1: The worldwide capacity of potential $\mathrm{CO}_{2}$ storage reservoirs

Table 2.2: Biomass production and carbon sequestration in tropical forests

Table 2.3: An average Carbon Stocks for Various Biomes

Table 2.4: Estimations of biomass and soil carbon

Table 2.5: Annual GPP of OTTER

Table 2.6: Photosynthetic parameters of different forest ecosystems

Table 2.7: Radiation interception, biomass production and RUE of selected tree species over a period of 303 days.

Table 2.8: Some of the indirect methods to derive plant canopy LAI

Table 2.9: Natural forest types in Sri Lanka

Table 2.10: Area of natural forest by national forest type classes in 1992 \& 1996

Table 3.1:Selected forest areas for the study in wet zone area in Sri Lanka

Table 3.2: Specifications of equipments used to acquire hemispherical photographs 113 
Table 4.1: Estimated total $\mathrm{CO}_{2}$ sequestration potential for selected natural vegetation types in wet zone area 


\section{LIST OF FIGURES}

Figure 3.1: Study sites under different vegetation types in wet zone of Sri Lanka

Figure 3.2: Schematic diagram of a section of line transect

Figure 3.3: Hemi photo camera assembly (Self leveling mount, fisheye lens and camera)

Figure 3.4: Setting up camera assembly, prior to taking a hemispherical photograph under a low canopy height at Thotupola kanda transect in HPNP.

Figure 3.5: Edited hemiphoto image in Hemiview window

Figure 4.1: Distribution of total canopy interception of Photosynthetically Active Radiation (PAR) by different vegetation types in wet zone region. $(\bullet)$ represents the mean value. The box represents the middle $50 \%$ of the total PAR interception data. The line through the box represents the median the PAR interception. The whiskers extending from the box represent the upper and lower $25 \%$ of the PAR interception data and $\left(^{*}\right)$ represent the outliers.

Figure 4.2: Canopy PAR interception as a fraction of total above canopy incident PAR of different vegetation types in wet zone region. The box represents the 
middle $50 \%$ of the fractional PAR interception. $(\bullet)$ represent mean values. The line through the box represents the median of the fractional PAR interception. The whiskers extending from the box represent the upper and lower $25 \%$ of the fractional PAR interception and (*) represent the outliers.

Figure 4.3: Variation of total PAR interception by forest canopies of selected study sites under different vegetation types in wet zone region. The box represents the middle $50 \%$ of the total PAR interception data. The line through the box represents the median of PAR interception and $(\bullet)$ represents the mean value. The whiskers extending from the box represent the upper and lower $25 \%$ of the PAR interception data and $(*)$ represents the outliers. $([\mathrm{M}]=$ Montane vegetation type; $[\mathrm{SM}]=\mathrm{Sub}$ montane vegetation type; $[\mathrm{SE}]=$ Semi evergreen vegetation type; $[\mathrm{LW}]=$ Lowland wet evergreen vegetation type).

Figure 4.4: Variation of total PAR interception by forest canopies of different elevational classes within 6 study sites (a) Sinharaja MAB; (b) Kanneliya FR; (c) Deanston area of Knuckles forest region; (d) Illukkumbura area of Knuckles forest region; (e) Peakwilderness sanctuary; (f) Horton Plains NP .The box represents the middle $50 \%$ of the total PAR interception data. The line through the box represents the median of PAR interception and (•) represents the mean value. The whiskers extending from the box 
represent the upper and lower $25 \%$ of the PAR interception data and $\left(^{*}\right)$ represents the outliers.

Figure 4.5: Variation of LAI by different vegetation types in wet zone region. $(\bullet)$ represents the mean value .The box represents the middle $50 \%$ of the total LAI data. The line through the box represents the median of LAI. The whiskers extending from the box represent the upper and lower $25 \%$ of the LAI data and $(*)$ represent the outliers of LAI data.

Figure 4.6: Variation of LAI of selected study sites under different vegetation types in wet zone region. The box represents the middle $50 \%$ of the LAI data. The line through the box represents the median of LAI and $(\bullet)$ represents the mean value of LAI. The whiskers extending from the box represent the upper and lower $25 \%$ of the LAI data and $(*)$ represents the outliers. $([\mathrm{M}]$ $=$ Montane vegetation type; $[\mathrm{SM}]=$ Sub montane vegetation type; $[\mathrm{SE}]=$ Semi evergreen vegetation type; $[\mathrm{LW}]=$ Lowland wet evergreen vegetation type).

Figure 4.7: Variation of LAI between different elevational classes within 6 study sites (a) Sinharaja MAB; (b) Kanneliya FR; (c) Deanston area of Knuckles forest region; (d) Illukkumbura area of Knuckles forest region; (e) Peakwilderness sanctuary; (f) Horton Plains NP .The box represents the middle $50 \%$ of the LAI data. The line through the box represents the median of LAI and $(\bullet)$ represents the mean value. The whiskers extending 
from the box represent the upper and lower $25 \%$ of the LAI data and $\left(^{*}\right)$ represents the outliers. Y axis label is same for all graphs.

Figure 4.8: Variation of LAI along elevational gradient in the wet zone of Sri Lanka. [S] represents the standard distance data values fall from the regression line; $[\mathrm{CI}]$ represents the confidence interval; $[\mathrm{PI}]$ represents the prediction interval, defined by lower and upper limits, which are calculated from the confidence level and the standard error of the prediction.

Figure 4.9: Relationship between LAI and fractional radiation interception by forest canopies in the wet zone of Sri Lanka. [S] represents the standard distance data values fall from the regression line; $[\mathrm{CI}]$ represents the confidence interval; $[\mathrm{PI}]$ represents the prediction interval, defined by lower and upper limits, which are calculated from the confidence level and the standard error of the prediction.

Figure 4.10: Regression line between remotely sensed PRI and corresponding PhRUE values estimated for subjectively selected sampling sites in wet zone area. [CI] represents the confidence interval; [PI] represents the prediction interval, defined by lower and upper limits, which are calculated from the confidence level and the standard error of the prediction.

Figure 4.11: Variation of mean values of remotely sensed PRI between different vegetation types in wet zone region. The box represents the middle $50 \%$ of the PRI. $(\bullet)$ represent mean values. The line through the box represents the 
median of the PRI. The whiskers extending from the box represent the upper and lower $25 \%$ of the PRI and $(*)$ represent the outliers.

Figure 4.12: Variation of mean values of remotely sensed PRI between different study sites in wet zone region. The box represents the middle $50 \%$ of the PRI data. The line through the box represents the median of PRI and $(\bullet)$ represents the mean value of PRI. The whiskers extending from the box represent the upper and lower $25 \%$ of the PRI data and $\left(^{*}\right)$ represents the outliers. $([\mathrm{M}]=$ Montane vegetation type; $[\mathrm{SM}]=$ Sub montane vegetation type; $[\mathrm{SE}]=$ Semi evergreen vegetation type; $[\mathrm{LW}]=$ Lowland wet evergreen vegetation type).

Figure 4.13: Variation of mean values derived PhRUE between different vegetation types in wet zone region. The box represents the middle $50 \%$ of the PhRUE. $(\bullet)$ represent mean values. The line through the box represents the median of the PhRUE. The whiskers extending from the box represent the upper and lower $25 \%$ of the PhRUE and (*) represent the outliers. $\quad 154$

Figure 4.14: Variation of mean values of PhRUE between different study sites in wet zone region. The box represents the middle $50 \%$ of the PhRUE data. The line through the box represents the median of PhRUE and $(\bullet)$ represents the mean value of PhRUE. The whiskers extending from the box represent the upper and lower $25 \%$ of the PhRUE data and $\left(^{*}\right)$ represents the outliers. $([\mathrm{M}]=$ Montane vegetation type; $[\mathrm{SM}]=$ Sub montane vegetation 
type; $[\mathrm{SE}]=$ Semi evergreen vegetation type; $[\mathrm{LW}]=$ Lowland wet evergreen vegetation type).

Figure 4.15: Variation of mean values of canopy level NPP between different vegetation types in wet zone region. The box represents the middle $50 \%$ of the NPP. $(\bullet)$ represent mean values. The line through the box represents the median of the NPP. The whiskers extending from the box represent the upper and lower $25 \%$ of the NPP and $(*)$ represent the outliers.

Figure 4.16: Variation of mean values of canopy level NPP between different study sites in wet zone region. The box represents the middle $50 \%$ of the canopy level NPP data. The line through the box represents the median of canopy level NPP and $(\bullet)$ represents the mean value of canopy level NPP. The whiskers extending from the box represent the upper and lower $25 \%$ of the canopy level NPP data and $(*)$ represents the outliers. $([\mathrm{M}]=$ Montane vegetation type; $[\mathrm{SM}]=$ Sub montane vegetation type; $[\mathrm{SE}]=$ Semi evergreen vegetation type; $[\mathrm{LW}]=$ Lowland wet evergreen vegetation type). $\quad 158$

Figure 4.17: Variation of canopy level NPP between different elevational classes within 6 study sites (a) Sinharaja MAB; (b) Kanneliya FR; (c) Deanston area of Knuckles forest region; (d) Illukkumbura area of Knuckles forest region; (e) Peakwilderness sanctuary; (f) Horton Plains NP .The box represents the middle $50 \%$ of the NPP data. The line through the box represents the median of NPP and $(\bullet)$ represents the mean value. The whiskers extending 
from the box represent the upper and lower $25 \%$ of the NPP data and $(*)$ represents the outliers. Axis label is same for all graphs.

Figure 4.18: Mean average net biomass production rate for different vegetation types in wet zone region. The box represents the middle $50 \%$ of the net biomass production rate and the vertical height of the box is proportionate to the sample size. $(\bullet)$ represent mean values. The line through the box represents the median of the net biomass production rate. The whiskers extending from the box represent the upper and lower $25 \%$ of the net biomass production rate.

Figure 4.19: Mean average net biomass production rate for different study sites. The box represents the middle $50 \%$ of the net biomass production rate and the vertical height of the box is proportionate to the sample size. $(\bullet)$ represent mean values. The line through the box represents the median of the net biomass production rate. The whiskers extending from the box represent the upper and lower $25 \%$ of the net biomass production rate. $(*)$ represents the outliers. $([\mathrm{M}]=$ Montane vegetation type; $[\mathrm{SM}]=$ Sub montane vegetation type; $[\mathrm{SE}]=$ Semi evergreen vegetation type; $[\mathrm{LW}]=$ Lowland wet evergreen vegetation type).

Figure 4.20: Mean average $\mathrm{CO}_{2}$ sequestration rate for different vegetation types in wet zone region. The box represents the middle $50 \%$ of the $\mathrm{CO}_{2}$ sequestration rate and the vertical height of the box is proportionate to the sample size. 
(•) represent mean values. The line through the box represents the median of the $\mathrm{CO}_{2}$ sequestration rate. The whiskers extending from the box represent the upper and lower $25 \%$ of the $\mathrm{CO}_{2}$ sequestration rate.

Figure 4.21: Mean average $\mathrm{CO}_{2}$ sequestration rate for different study sites. The box represents the middle $50 \%$ of the $\mathrm{CO}_{2}$ sequestration rate and the vertical height of the box is proportionate to the sample size. $(\bullet)$ represent mean values. The line through the box represents the median of the $\mathrm{CO}_{2}$ sequestration rate. The whiskers extending from the box represent the upper and lower $25 \%$ of the $\mathrm{CO}_{2}$ sequestration rate. $\left(^{*}\right)$ represents the outliers. $([\mathrm{M}]=$ Montane vegetation type; $[\mathrm{SM}]=$ Sub montane vegetation type; $[\mathrm{SE}]=$ Semi evergreen vegetation type; $[\mathrm{LW}]=$ Lowland wet evergreen vegetation type).

Figure 4.22: Variation of canopy level NPP with LAI wet zone of Sri Lanka. [S] represents the standard distance data values fall from the regression line; [CI] represents the confidence interval;[PI] represents the prediction interval, defined by lower and upper limits, which are calculated from the confidence level and the standard error of the prediction.

Figure 4.23: Relationship between $\mathrm{CO}_{2}$ sequestration rates with NDVI in wet zone of Sri Lanka. [S] represents the standard distance data values fall from the regression line; $[\mathrm{CI}]$ represents the confidence interval; $[\mathrm{PI}]$ represents the prediction interval, defined by lower and upper limits, which are 
calculated from the confidence level and the standard error of the prediction.

Figure 4.24: Relationship between $\mathrm{CO}_{2}$ sequestration rates with EVI in wet zone of Sri Lanka. [S] represents the standard distance data values fall from the regression line; $[\mathrm{CI}]$ represents the confidence interval; $[\mathrm{PI}]$ represents the prediction interval, defined by lower and upper limits, which are calculated from the confidence level and the standard error of the prediction. 


\section{DEDICATION}

To

Appachchi, Ammi \& Panchi (Kasundhi) 


\title{
Determination of the biomass production and carbon sequestration capacity of wet - zone forests in Sri Lanka
}

\section{Wahala Mudiyanselage Palitha Sampath Bandara Wahala}

\begin{abstract}
Despite the recognized potential of forests as an important sink to sequester carbon, accurate estimates of the carbon sequestration potential of different ecosystems or their component species are lacking, especially for the different forest types present in Sri Lanka. The primary objective of the study is to determine the carbon sequestration potential of selected important natural forest ecosystems in the wet zone of Sri Lanka. In this study, completely non destructive approach, based on the basic physiology of biomass production process was used to estimate the carbon sequestration potential as a rate in ecosystem scale. Monteith $(1972,1977)$ showed that the rate of biomass production is directly proportionate to the amount of radiation intercepted by the foliage canopy. The above relationship can be given as: $\mathrm{W}=\mathrm{e} \mathrm{R}_{\mathrm{I}}$, Where, $\mathrm{W}$ is the amount of total biomass (above and belowground biomass) produced and $\mathrm{R}_{\mathrm{I}}$ is the amount of radiation intercepted by canopy. The proportionality constant, $\mathbf{e}$ is termed as Radiation Use Efficiency (RUE). These two variables $\left(R_{I}\right.$ and e) were determined explicitly for specific vegetation types using different approaches. $\mathrm{R}_{\mathrm{I}}$ values were estimated using hemispherical photographs obtained from 337 sampling points representing 44 transect covering four major vegetation types in wet zone in Sri Lanka. RUE values were
\end{abstract}


derived by canopy level photosynthesis termed as photosynthetic RUE (PhRUE) (with generalized photosynthetic parameters) at selected locations and stand level PhRUE values were derived for each transect in each vegetation type, with the relationship developed between PhRUE and Photochemical Reflectance Index (PRI) which was developed using MODIS (Moderate Resolution Imaging Spectroradiometer) data using satellite image analysis program ENVI 4.5. The canopy level net primary production was highest in lowland wet evergreen forests which was represented by Sinharaja Forest Reserve and Kanneliya Forest Reserve $\left(8.615 \pm 1.902 \mathrm{c}\right.$ tons $\left.\mathrm{ha}^{-1} \mathrm{yr}^{-1}\right)$ and the lowest in Montane forests represented by Horton Plains National Park and upper reaches of the Peak Wilderness Sanctuary $\left(1.535 \pm 0.473 \mathrm{c}\right.$ tons $\left.\mathrm{ha}^{-1} \mathrm{yr}^{-1}\right)$. With regard to the net biomass production, the highest values were recorded in the lowland wet evergreen forests $\left(18.02 \pm 4.264 \mathrm{tha}^{-1} \mathrm{yr}^{-1}\right)$ for Sinharaja Forest Reserve and $15.847 \pm 2.258 \mathrm{tha}^{-1}$ $\mathrm{yr}^{-1}$ for the Kanneliya Forest Reserve, while the value for the sub montane zone represented by the Peak Wilderness Sanctuary as $13.417 \pm 1.841 \mathrm{t} \mathrm{ha}^{-1} \mathrm{yr}^{-1}$, KnucklesIllukkumbura as $6.410 \pm 4.690 \mathrm{t} \mathrm{ha}^{-1} \mathrm{yr}^{-1}$, Knuckles-Deanston area as $5.204 \pm 2.091 \mathrm{t}$ $\mathrm{ha}^{-1} \mathrm{yr}^{-1}$ and . Knuckles-Illukkumbura as $6.904 \pm 0.965 \mathrm{t} \mathrm{ha}^{-1} \mathrm{yr}^{-1}$ represent the semi evergreen vegetation type and Montane zone represented by the Horton Plains National Park as $3.442 \mathrm{t} \mathrm{ha}^{-1} \mathrm{yr}^{-1} 0.957$ and upper reaches of the Peak Wilderness Sanctuary (as $2.329 \pm 0.169 \mathrm{t} \mathrm{ha}^{-1} \mathrm{yr}^{-1}$ ). Canopy level Radiation Use Efficiency (PhRUE), values varied with the forest type as well as the elevation. The highest levels of $0.0058 \pm$ 0.0013 ( $\mathrm{mol} \mathrm{CO} 2 / \mathrm{mol}$ PAR) were observed from Lowland tropical evergreen forests while the lowest values of $0.001007 \pm 0.000290(\mathrm{~mol} \mathrm{CO} 2 / \mathrm{mol} \mathrm{PAR})$ were observed from the montane forests. NDVI (Normalized Different Vegetation Index) and EVI 
(Enhanced Vegetation Index) were also derived using MODIS data to develop model between $\mathrm{CO}_{2}$ sequestration rate and these vegetation index as a tool to extrapolate values to estimate for known extents of selected vegetation types. This study was confined to the natural forests of the wet zone of Sri Lanka. The methodology used should be extended to the other forest types in Sri Lanka including dry mixed evergreen forests and mangroves to get a comprehensive understanding of the net primary production and carbon sequestration capacity of the natural forests in the country. 